\title{
Entre las distorsiones de las guitarras eléctricas y el charango: sónica, cuerpo y performance en las prácticas sonoro-musicales de los jóvenes músicos emberá chamí (Colombia)
}

\author{
Juan Carlos Molano Zuluaga \\ Universidade Federal do Rio Grande do Sul (Brasil) \\ juanmolano21@hotmail.com
}

RESUMEN

Este artículo se enmarca dentro de unas interpretaciones etnomusicológicas dadas por mi trabajo de campo en el resguardo indígena Emberá Chami de San Lorenzo, en el cual el insumo u objetivo principal fue remitirme a una etnografia de los grupos de música de los jóvenes indigenas. En este sentido, este trabajo evidencia significaciones de performance musical a partir de un evento de punk-rock indigena que aconteció en una de las comunidades más encumbradas del resguardo de San Lorenzo y que fue insumo para denotar ciertas resistencias políticas y devenires corporales y sónicos en el territorio. La intención es demostrar los significados sociomusicales y sociopolíticos que estos jóvenes músicos atribuyen a sus prácticas sonoro-performáticas, privilegiando en este caso las tensiones generadas entre estos músicos actores sociales, los residentes y los gobernantes del territorio, por la disposición sónica que estos jóvenes atribuyen a sus prácticas sonoro-musicales.

Los jóvenes indígenas emberá chamí están elaborando otro camino de lucha y resistencia indigena, y para que sus voces sean escuchadas, las promulgan con sus prácticas sonoro-performáticas. A partir de estas interpretaciones, se concluye que el modo de serlestar indígena emberá en San Lorenzo se evidencia a través de ciertas performances identitarias que se han consolidado 
por la apropiación, escucha y práctica del punk-rock y la música andina peruano-boliviana.

Palabras clave: prácticas sonoro-musicales, emberá chamí, etnomusicología, indígenas Colombia.

\section{Between the distortions of the electric guitars and the charango: sonic, body and performance in the sound-musical practices of the young musicians Emberá Chamí (Colombia)}

ABSTRACT

This article is framed in the ethnomusicological interpretations deducted in my field work, in the Emberá Chami indigenous resguardo in San Lorenzo; in this, the main objective was referring my work in an ethnography of the musical groups of indigenous youths. In this sense, this work evidences musical performance though a punk-rock event made in one of the most encumbered communities in San Lorenzo resguardo and it was denote certain political resistances, corporal and sonic behaviors in the territory. The intention is showing the socio-musical and socio-political meanings that these young musicians attribute to their sound-performance practices, privileging in this case, the tensions generated between: musicians, social actors, residents and the governors of the territory, by the sonic position that these young people attributes to their soundmusical practices.

The Emberá Chamí indigenous youth are making different ways of fighting and resistance in order to their voices would be listening, they promulgate them with their sonorous performance practices. With these interpretations just concluding that the Emberá indigenous way of being / stay in San Lorenzo, is evidenced of through certain interpretations so that have been consolidated by the appropriation, listening and practice of punk-rock and Peruvian-Bolivian Andina music.

Keywords: sound-musical practices, Emberá Chamí, ethnomusicology, indigenous Colombia. 
Los emberá, êbêra o ẽpẽrá, también llamados chocó, son un pueblo amerindio que habita en algunas zonas del litoral Pacífico y zonas adyacentes de Colombia, el nororiente de Panamá y el noroccidente del Ecuador. Los que habitan los Andes colombianos se conocen como emberá chamí o «personas de la montaña», que por distintos motivos sociopolíticos han seguido un patrón de poblamiento disperso entre las cordilleras central y occidental. Así como sucede con la lógica predominante con otras sociedades amerindias, entre los emberá chamí la construcción de personas y cuerpos (Seeger, Da Matta y Viveiros de Castro, 1979) se constituye como un dispositivo político importante para hacer visibles sus territorios y sociedades, especialmente, por los más jóvenes, que manifiestan un marcado interés por desenvolver, a través de ciertas performatividades, posiciones sobre la diferencia cultural.

Este artículo da cuenta de un inusitado activismo indígena por jóvenes músicos emberá chamí, a través de ciertos procesos y tratamientos corporales dados por las prácticas sonoro-performáticas. El modo de ser/estar emberá chamí en el territorio indígena está determinado por un conflictivo escenario histórico-político, donde las prácticas culturales — especialmente la danza y la música - se constituyen como un insumo importante para provocar ciertos devenires de cuerpo(s) y territorio(s). Las distintas dimensiones estéticas dadas por sus corporalidades y las «intensas» vocalidades y sonoridades en sus prácticas sonoro-musicales determinan la constitución de la persona indígena emberá chamí en términos sonoros.

\section{ENCUENTRO CON LOS JÓVENES MÚSICOS EMBERÁ}

En una ocasión, cuando realizaba mi trabajo de campo ${ }^{1}$, fui invitado por el gobernador del resguardo ${ }^{2}$ indígena de San Lorenzo ${ }^{3}$ a una de las reuniones

1 Esta investigación fue desarrollada en el programa de Pos-Graduación en Música (PPGMUS) de la Universidade Federal do Rio Grande do Sul (UFRGS), con financiamiento de la CAPES (2014-2015), y resultó en la disertación «Damaciri y Jaury: La performatividad sonora Emberá Chamí en el resguardo indígena de San Lorenzo. Caldas (Colombia)» (2016), accesible en http://www.lume.ufrgs.br/handle/10183/142688.

2 Resguardo es el territorio de la comunidad reconocido legalmente. La propiedad del territorio es comunitaria. Sus tierras son inembargables, imprescriptibles e inajenables (según determina el artículo 329 de la Constitución colombiana de 1991).

3 El resguardo indígena de San Lorenzo es un territorio andino localizado en el noroccidente del departamento de Caldas (Colombia), con una extensión de 6000 hectáreas y donde habitan aproximadamente 11618 indígenas. 
del cabildo ${ }^{4}$, que se celebran usualmente en el polideportivo del territorio. Al entrar, observé allí sentados en semicírculo a los cabildantes de las veintidós comunidades indígenas, algunos asistentes no indígenas - que forman parte activa mostrando su solidaridad con la lucha emberá ${ }^{5}$-, algunos residentes del territorio y el gobernador del resguardo. En esta ocasión, la discusión giraba en torno a la resistencia indígena y la «crisis» de la identidad emberá, como algunos indígenas la llamaron ${ }^{6}$. No quiero hacer referencia de todo el evento en particular, sino más bien acotar la interacción de los asistentes frente a algunas posiciones enmarcadas precisamente en el concepto de identidad. Expresiones como «identidades dormidas», «fortalecimiento indígena» $\mathrm{y}$ «enfoque diferencial» dan luz para entender el sentido en el que emergieron estos diálogos.

Al salir de la reunión y recorrer los distintos caminos del centro poblado ${ }^{7}$, fue notable ver a jóvenes indígenas que al momento se encontraban saliendo del colegio y de la casa de la cultura. Algunos de ellos llamaron mi atención por su indumentaria estética: camisetas negras alusivas a grupos de rock pesado, uso de cresta y piercing en sus rostros, chaquetas con leyendas anarco-punk y mochilas que dejaban ver en su interior quenas y zampoñas. Así pues, mientras observaba a estos jóvenes, demarqué cada uno de los postulados de la reunión del cabildo y precisé algunos interrogantes, como: ¿qué se entiende y qué sienten estos jóvenes con respecto a su identidad e indigenidad? ¿Qué es ser un joven músico indígena emberá chamí hoy en el territorio?

Algunos de estos jóvenes forman parte activa de un grupo juvenil de la casa de la cultura, en el cual toman partida de su pensamiento ancestral y territorial

$4 \quad$ Es el estamento del gobierno indígena. Son electos por votación interna anualmente y es allí donde se toman todas las decisiones del territorio.

5 La lucha emberá chamí se ha posicionado en este territorio indígena con más vehemencia y ahínco en las últimas décadas, precisamente por los distintos eventos político-sociales que han maltratado y golpeado espacios e identidades. Sucesos como la pérdida del territorio en el año 1943 y posteriormente su recuperación en el año 1983, el conflicto armado y el crecimiento de empresas mineras y multinacionales en el sector denotan un fuerte e inusitado activismo indígena en la región.

6 Esta alusión connota directrices para entender la identidad indígena emberá chamí como un dispositivo de lucha y resistencia en el siglo XXI. Es decir, la identidad como estrategia e insumo cosmopolítico para visibilizar ciertas agendas frente al Estado colombiano. La mención de «crisis» de la identidad emberá podría entenderse como la necesidad de salvaguardar costumbres identitarias o denotar «otras» consecuciones de performatividad identitaria indígena en el territorio.

7 Es el lugar donde más se densifica la población en el resguardo; allí se encuentran las instalaciones del gobierno indígena, la iglesia, el colegio, el centro de salud y otros sitios de consumo habitual para sus residentes. 
mediante las prácticas culturales de la artesanía, la danza, la música, la educación indígena y los talleres de la lengua emberá; también se identifican como parte de un «movimiento» punk, el cual está reflejado en sus grupos de rock-punk indígena en el territorio, llamados Gozque y Estado K-lavera ${ }^{8}$. A estos jóvenes no les importa que les digan que lo que ellos interpretan provenga de una moda foránea o se adjudique que lo hacen por ser adolescentes en «época de rebeldía». Simplemente, como me expresaron algunos de ellos, están pregonando un indigenismo de una forma muy particular, una forma de vida que quiere ir en contra de todo sistema. Fernando es un joven músico indígena de veintiún años residente en el resguardo y lo explica así:

[...] Obviamente somos rebeldes a un sistema, a una forma de vida impuesta, a un régimen de cadenas invisibles que tan fuerte atan [...] ahora, hoy por hoy entendemos muchas cosas, como por ejemplo de que estando dentro de un resguardo indígena no sentimos la diferencia a un territorio común y corriente $[\ldots]$ no desconocemos que el rock influyó mucho en nosotros, porque el punk nos concedió un pensamiento de izquierda, contracorriente y revolucionario.

Las palabras de este joven denotan las irregularidades de un sistema político de Estado que permea estas comunidades, obedeciendo a momentos de zozobra y desasosiego por las personas en sus espacios y parcelas - especialmente por el conflicto armado, que dejó considerables huellas en este territorio9-. Igualmente, la afirmación de este joven: «[...] ahora, hoy por hoy, entendemos muchas cosas» denota el momento, el tiempo, el instante de impulsar en ellos una acción frente a las adversidades y donde estas performances identitarias y sonidos contribuyen a estimular un pensamiento marcado y delineado por estas improntas.

Entonces, ¿cómo es que estas prácticas de punk-rock llegan a tener tanto valor para estos jóvenes dentro del territorio y cómo ingresan a él? Para discurrir esto,

8 Estos grupos de rock-punk fueron consolidados por estos jóvenes en el año 2008, precisamente por la llegada al territorio indígena de algunos bienes de consumo como los casetes, los CD, la internet, y posteriormente los equipos tecnológicos e instrumentos eléctricos musicales.

9 Según Plan de Salvaguarda pueblo emberá de Caldas: «Nuestro territorio ha sido escenario de confrontaciones armadas ajenas a los indígenas en varias ocasiones. 1. En la independencia por ser frontera entre las fuerzas patriotas de Antioquia y las tropas realistas del Cauca (1813-1819); 2. En las guerras civiles del siglo XIX, por ser frontera entre las fuerzas conservadoras de Antioquia y las fuerzas liberales del Cauca (1850-1902); 3. En la época de la violencia por el enfrentamiento entre los partidos liberal y conservador (1940-1960); 4. En el conflicto armado interno, por ser territorio estratégico para el paso entre el Chocó y el centro del país, por el acceso y control de los recursos naturales existentes en el territorio y la disputa entre los diferentes grupos armados (1970-2016)». 
Fernando, en una comunicación virtual ${ }^{10}$, me ofrece información sobre los inicios de estas prácticas musicales en San Lorenzo, compartiendo conmigo un artículo escrito por ellos mismos y que fue un insumo para hacer frente a una resistencia por la negación de algunos sectores a la realización de estas prácticas sonoroperfomáticas en el territorio indígena. Los usos y propósitos de esta información, inicialmente, no fueron más allá de enmarcar los inicios de estas prácticas sonoromusicales de punk-rock en el territorio indígena.

[...] desde hace algunos años, en el resguardo indígena, algunos de nosotros adoptamos el rock como género de nuestra preferencia [...] después de algún tiempo, el rock empieza a tornarse como un objetivo, como un grito al viento que reclama, así se empieza a conseguir instrumentos, a intentar interpretarlos. Se consolida pues alguna banda [grupo musical] que a contracorriente y sin un público se machaca ${ }^{11}$ en las casas de sus integrantes intentando hacer algo parecido al rock [...] el proceso desde el primer álbum de alguna banda [aquí] lleva sus años, podemos hablar del 2003 y un casete con algunas canciones que escuchábamos, además de muchas decepciones, hasta que en algún momento, pasando por los instrumentos que se consiguen, se llega a conocer una escena un poco más grande $\mathrm{y}$, por decirlo de alguna manera, con más experiencia. [...] con ideas más estructuradas, con ese empujón que se necesitaba, se decide hacer un primer evento, un primer toque. Se logra conseguir el lugar, se logra conseguir un modesto sonido, algunas bandas, y lo más importante, un público, también modesto, pero al fin y al cabo un público. Los ánimos van creciendo, tanto que unos meses después se decide hacer otro evento, ya con una experiencia previa; le damos un nombre Rock N Roll Attack ${ }^{12}[\ldots]$ mejor sonido, más bandas, más público; ya no éramos los cinco peleles ${ }^{13}$ de un colegio que intentábamos hacer música.

Siguiendo estas líneas, ya podía pensar sobre algunos episodios y eventos musicales que han marcado desde hace un poco más de una década el territorio indígena, por esa nueva generación de jóvenes que han conformado un grupo de actividad sociocultural dentro del territorio en procura de liberar ese pensamiento

10 En ese sentido, fueron muy significativos los diálogos y encuentros que tuve dentro del territorio indígena, precisamente, para aproximar estas interpretaciones etnomusicológicas. Sin embargo, debo acotar que estos diálogos igualmente se demarcaron por las distintas redes sociales virtuales, especialmente Facebook y YouTube, por algunas dinámicas convenientes que eran las de compartir vis a vis videos, fotos, archivos y links de páginas web.

11 Categoría nativa que hace alusión a algo que se trabaja mucho y con algún grado de dificultad.

12 Es el nombre del festival de rock-punk que estos jóvenes han consolidado en el territorio indígena. A este festival son invitados grupos musicales de otros municipios cercanos al resguardo, como Supía y Riosucio, y hasta la fecha lleva diez versiones realizadas.

13 Categoría que hace alusión a una persona débil o de poco carácter. 
indígena, que en su momento - como me expresaron algunos de ellos — no alcanzaron a conocer sus padres o abuelos. Por otro lado, las acciones de estos jóvenes, con sus prácticas sonoro-performáticas, despliegan otras formas de consecución y pensamiento indígena en cuanto a su construcción identitaria y producción sónica, precisamente relacionada con la apropiación de ciertos elementos simbólicos y artefactos sonoros concedidos por otro(s) plano(s) material(es). Entonces, ¿cómo es la relación cosmontológica y cosmosónica ${ }^{14}$ para con estos artefactos tecnológicos? ${ }^{15}$ En este sentido, estos jóvenes perfilan formas distintas de escucha y producción sónica en el territorio, determinadas principalmente por las intensidades sonoras de estos equipos tecnológicos. Asimismo, están siendo «perturbadores sónicos» dentro del territorio, haciendo alusión a las manifestaciones del cabildo indígena y sus residentes cuando denotan estas prácticas sonoro-musicales como una reproducción de una cultura foránea que no forma parte ancestral ni territorial del pueblo emberá ${ }^{16}$.

\section{EL PUNK-ROCK DE LOS JÓVENES INDÍGENAS}

Los métodos en cuestión de pensar y acceder a las prácticas sonoro-musicales de estos jóvenes dentro del territorio siempre se conjugaron en el día a día vivido y transcurrido en campo. Intentar descifrar algunos rumbos importantes de cada uno de estos eventos, entendiendo los significados que estos actores sociales atribuyen

14 La cosmosónica es una categoría de Stein (2009) de la cual delineo y solvento las interpretaciones sonoro-musicales emberá. Esta autora, en su trabajo de tesis titulado «Kyringüé Mboraí: os cantos das crianças e a cosmo-sônica Mbyá-Guarani», elaboró un concepto-síntesis de las fuertes imbricaciones entre las dimensiones sociocosmológica y sonora al que nombró cosmosónica. En palabras de la autora, «este término apunta a la centralidad del ámbito sonoro en el modo de ser Mbyá, subrayo, desde ya, que la 'cosmo-sónica' más precisamente debería ser acuñada como 'sociocosmo-sónica' por envolver el campo social, constituido también por la musicalidad, entre tanto, por creer que la sonoridad 'cosmo-sónica' es más accesible a los oídos y a los diálogos, preferí omitir lo socio y producir una metonimia, sugiriendo que en el cosmo se incluyen las relaciones humanas y extra humanas» (Stein, 2009, p. 24).

15 En este sentido, cabe mencionar que la intención aquí no es delinear este pensamiento desde una posición mimética, como menciona Taussig (1993), sino desde una «dimensionalidad estética sonora» como afirma Ferreira. En palabras de este último autor, «tratamos el contexto maquínico [...] primero considerando las influencias de transformaciones tecnológicas sobre la sensibilidad y percepción sonora» (Ferreira, 2006, p. 29). Es decir, nociones de una perspectiva maquínica a la que nunca habían respondido estos actores sociales con estos artefactos tecnológicos, considerando así mismo «nuevas» significaciones de escucha a través de estas máquinas $\mathrm{y}$, por tanto, delineando otro pensamiento cosmosónico en el territorio.

16 El cabildo indígena, encabezado por su gobernador, sus cabildantes y algunos residentes - especialmente los adultos y ancianos_-, manifiestan resistencia por la intervención de estas prácticas de punk-rock en el territorio indígena. 
a sus prácticas sonoro-musicales en cada uno de los espacios de sociabilidad, siempre fue el motor e impulso de este estudio etnomusicológico. En otras palabras, el insumo esencial etnográfico musical (Seeger, 2008), basado en el estudio de las performances musicales de estos jóvenes indígenas en San Lorenzo, fueron el principal vínculo de acceso a interpretaciones etnomusicológicas.

En este sentido, el siguiente relato se constituye como el punto de partida de estas interpretaciones sociopolítico-musicales, dadas a través de las distintas categorías émicas relacionadas con ese ámbito sonoro - la cosmosónica de los jóvenes músicos indígenas Emberá-, como también vinculadas con las significaciones de construcción de persona, etnia y territorio.

Fernando: [...] Para la sexta versión del festival [Rock N Roll Attack], contábamos con algunos sentimientos de incertidumbre, porque no sabíamos la acogida que el público iba a tener en cuanto al lugar.

Juan Carlos: ¿Dónde siempre realizan el festival?

Víctor: La mayoría de versiones se hacían en el centro del pensamiento [polideportivo del territorio], con el compromiso de dejar limpio el espacio y pagar la energía eléctrica del lugar. [...] Lastimosamente no tenemos entidades que nos patrocinen este evento, es totalmente guerreado ${ }^{17}$ por nosotros, entonces... de esto nos tocaba pagar el sonido, que es alquilado, y en una ocasión desafortunadamente no pudimos pagar la energía. Creo que este fue el motivo que estaban buscando [el cabildo indígena] desde hace rato para sacarnos del lugar. Entonces nos dijeron que consiguiéramos otro espacio, en pocas palabras creo que más bien querían que no hiciéramos más el evento.

Juan Carlos: ¿Y ahora en esta ocasión dónde hicieron el festival?

Fernando: En la comunidad de Blandón, queda a más de media hora caminando desde el centro poblado; uno de nuestros amigos ofreció su casa para realizarlo allá.

Juan Carlos: ¿Cómo fue el desplazamiento con equipos de sonido e instrumentos hasta la comunidad?

Víctor: Fue muy difícil, porque igualmente el acceso a la comunidad en carro es imposible, nos tocó subir en jeep ${ }^{18}$ hasta cierto punto con los equipos de sonido e instrumentos musicales y de ahí luego bajar todas las cosas del jeep para llevarlas a pie hasta la comunidad, nos tocó muy duro. Igualmente varias personas nos colaboraron.

17 Término usado para designar algo «muy trabajado», con mucha dificultad.

18 Es un vehículo antiguo de carga muy usado en esta región del país. 
Foto 1. Jóvenes indígenas punkrock en el festival Rock $N$ Roll Attack (foto tomada de la página oficial del evento en Facebook).

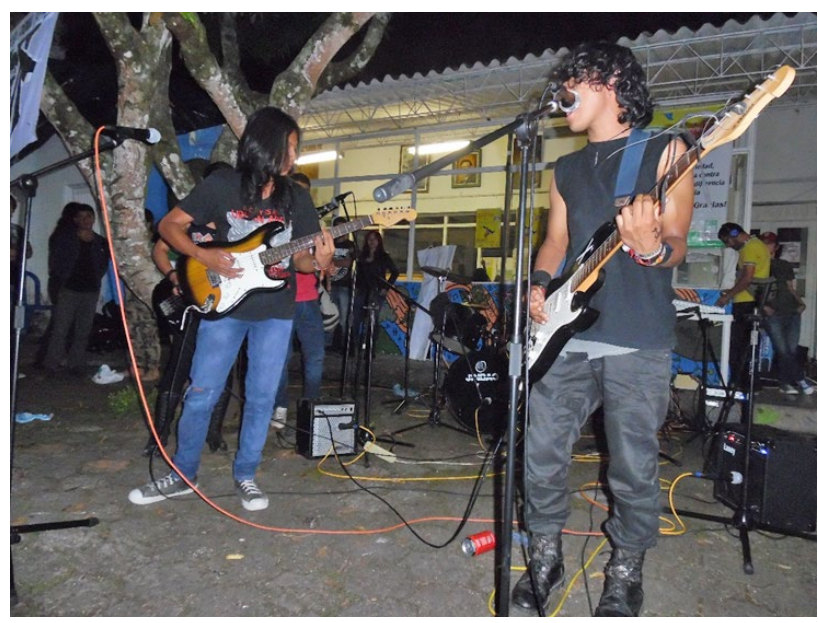

Juan Carlos: ¿Pero ustedes informaron al cabildo indígena para la realización de este evento en la comunidad?

Fernando: No, porque nosotros hemos notado que no tenemos mucha aceptación por la realización de estos toques acá, [...] en esta ocasión nosotros le informamos solo al cabildante de la comunidad de Blandón.

Víctor: Fue muy intenso, porque después del evento muchos cabildantes se dieron cuenta, al igual que el gobernador, y fue motivo de discusiones. A ellos no les gustó.

Juan Carlos: ¿Y cómo fue el evento en la comunidad? ¿Qué pasó allá?

Víctor: Con gran sorpresa uno a uno de nuestros amigos fueron llegando, vinieron a pie desde el centro poblado y comunidades aledañas, fue un total éxito [...] al momento de llegar a Blandón, pues todos nos organizamos para adecuar el espacio; era en un patio pequeño, pero ahí pudimos organizar el sonido para que las bandas tocaran.

En este sentido, la imagen del jeep subiendo por la difícil y encumbrada montaña del territorio la pienso aquí como una metáfora. ¿Cuál es la simbología remanente detrás de este hecho? Es importante mencionar que el evento como tal de estos jóvenes marcó e interrumpió en algo la tranquilidad del territorio, y cuando hablo de interrumpir la tranquilidad, me refiero a algo extraño o extraordinario para un espacio donde sus residentes poseen un fuerte vínculo ancestral y territorial. 
Ahora bien, la metáfora a la que me refiero es el jeep como vehículo de metamorfosis de un territorio, de unos cuerpos y de unos sonidos que se funden mediante el hecho extraño o extraordinario que es el evento mismo. Como cuando Kafka (1915), en La Metamorfosis, incorpora un hecho inexplicable, que es la transformación de Gregorio Samsa en un animal, y que esta transformación no es comprendida por nosotros ni por los mismos personajes del relato. Asimismo, se pudo reflejar este evento en el territorio, el cual no fue comprendido por muchos de sus residentes y tampoco por personas ajenas a él —como yo, por ejemplo, que tardé en darle un significado simbólico y remanente al evento narrado-.

El filósofo marxista checo Kosik (1996), en una alusión a este clásico de la literatura de Kafka, llama la atención de que el personaje central de La Metamorfosis no es Gregor Samsa sino su hermana Grete. Como acota el autor «[...] la transformación grotesca se consuma, de hecho, cuando Grete deja de percibir en su hermano un humano. Ella ya no sabe si él es gente o un animal» (Kosik, 1996, p. 4). Más adelante afirma: «[...] si fuera mi hermano y fuera humano, tendría en relación a la familia un sentimiento de consideración, evitaría perturbarles la tranquilidad y saldría de la casa por su propia iniciativa» (Kosik, 1996, p. 4).

El evento mismo de los jóvenes músicos indígenas se delinea aquí siguiendo esta metáfora de Kafka y esbozando el siguiente interrogante: ¿no sería, en alguna medida, esta la situación de los jóvenes indígenas del territorio, de ser «perturbadores» de los órdenes instituidos territorialmente y que en alguna medida precisan ser removidos, de forma de no «alterar» cierto orden estable e imperturbable de la «tradición», anclada como un ciclo de perpetuación de la identidad a través de los tiempos? En este sentido, ese movimiento es atribuido a esta nueva generación de jóvenes indígenas que se constituyen como los vectores centrales de esa producción de «ruidos»y sonidos, con artefactos tecnológicos capaces de provocar e instigar.

\section{Desterritorialización sónica y reterritorialización sónica}

Las tensiones fueron manifiestas entre el cabildo indígena y los jóvenes músicos por la realización de estas prácticas sonoro-musicales en el territorio. El estamento indígena declaró que, sonoramente, irrumpen en la tranquilidad cotidiana de ciertos espacios. Así pues, por disposiciones políticas estas prácticas sonoromusicales son «desterritorializadas» y por ningún motivo lúdico, político o social los jóvenes deben performatizar estas prácticas en San Lorenzo. Es decir, a lo que hago mención es a una desterritorialización sónica como elemento contundente 
para dar cuenta primeramente a un movimiento de salida del territorio y segundo a una «multiterritorialidad» desplegada por estos jóvenes actores sociales. Como afirma Fernando:

[...] nos tocó buscar otro espacio, fuera de San Lorenzo [...] pero no todo es lo que parece, es una persecución contra nosotros, no solo a nivel del resguardo indígena sino a nivel municipal $[\ldots]$ hacen alusión a la incursión de una cultura foránea dentro del territorio, sabiendo que si tomamos algo de otra cultura es precisamente para transformar la nuestra y eso es lo que hacemos, es una lucha, una resistencia frente a muchas cosas que pasan en nuestro territorio y el punk nos sirvió para ver más allá frente a la cuestión de las ideas, de las posturas, de la rebeldía frente al sistema. [...] hoy por hoy [nosotros] como emberás seguimos manteniendo esa rebeldía. Antes que nada somos indígenas emberás, pero tomamos estas herramientas de la ciudad. [...] algunas personas del territorio nos rechazan, porque pensamos así o porque simplemente nos vestimos así [...] en ocasiones no nos toman como una expresión del pueblo emberá, ¡el emberá no se congeló en el tiempo! [...] ahora tenemos que pensar dónde realizar nuestro festival, nuestros toques; nos han sacado de estas tierras, pero la lucha continúa porque estos sonidos son de nuestro territorio ${ }^{19}$.

En este sentido, siguiendo a Deleuze y Guattari, «toda sociedad, sino también cualquier individuo, es atravesado por dos segmentaridades al mismo tiempo: una molar y otra molecular. Siempre una presupone la otra. En resumen, todo es político, además toda política es al mismo tiempo macropolítca y micropolítica» (Deleuze y Guattari, 1996, p. 90).

De acuerdo con los autores, tanto los individuos como los grupos estamos constituidos por «líneas» de diversa naturaleza, y en este caso el evento político que demarco en este artículo está delineado por estas líneas de fuga o de «desterritorialización». Es decir, trazos imaginarios que no son segmentarios, simplemente se componen sin saber de antemano lo que va a funcionar. Entonces, ¿qué va a funcionar? Esta es la pregunta que delimitaré aquí, siguiendo estos pliegues constitutivos por estas «líneas» que se proyectan afuera y apuntan a movimientos que llevan a un devenir-sónico y devenir-territorio. En este sentido, como expresan Guattari y Rolnik (1996), de «proposición maquínica», en el cual todo movimiento de «desterritorialización» comprende concomitantemente un movimiento de «reterritorialización».

19 Los jóvenes llevaron su festival de rock-punk al municipio de Riosucio, próximo a San Lorenzo. Allí, estos jóvenes desplegaron toda su logística para preparar las próximas versiones del festival en un lugar prestado y acondicionado para el evento. 
Jamás se desterritorializa por sí solo, por lo mismo se necesitan dos términos. En cada uno de los términos se reterritorializa uno en otro. De tal manera que no se debe confundir la reterritorialización con el retorno a una territorialidad primitiva, o más antigua: ella implica necesariamente un conjunto de artificios por los cuales un elemento, el mismo desterritorializado, sirve de territorialidad nueva a otro que pierde la suya. De allí todo un sistema de reterritorializaciones horizontales y complementarias» (Guattari y Rolnik, 1996, p. 41).

Este proceso se produce sobre estas líneas de fuga, acudiendo a algo que se construye en un plano de consistencia, algo devino otra cosa y nada será igual, son consideradas primordiales, por el poder de transformación o metamorfosis que cargan. Así pues, esta mención de desterritorialización sónica se asume como elemento constitutivo y fundante hacia un devenir cuerpo y territorio. Es decir, hacia un aparecimiento de algo «nuevo» que se da en esa proyección de líneas de fuga, a través de ese despliegue de nuevas territorialidades y proyectado en una reterritorialización sónica. Ahora bien, ¿cómo está integrado ese proceso de reterritorializacion sónica? Es el interrogante que delineará las siguientes interpretaciones relacionadas con una metamorfosis sónica-corporal de estos jóvenes músicos, como una estrategia cosmopolítica para denotar otras posibilidades perceptivas a sus dirigentes y residentes del territorio indígena.

\section{EL DEVENIR SÓNICO: JAURY COMO SÍMBOLO DE RETERRITORIALIZACIÓN SÓNICA}

Al encontrarme en uno de esos días de trabajo de campo en el centro poblado, alistando mi cámara y otros equipos tecnológicos para grabar algún material de audio, observo que a la distancia algunos jóvenes entran a la casa de la cultura cargando equipos de sonido. Al percatarse ellos de mi presencia, soy invitado a pasar al sótano de la casa — que es precisamente el espacio de encuentro de los jóvenes y de intervención de sus prácticas sonoro-musicales-, para asistir y escuchar la performance musical. Mientras observo toda la disposición para con el espacio y la amplificación de algunos instrumentos musicales, denoto ciertas particularidades en el ambiente que asumen una transformación o metamorfosis. Es decir, estos jóvenes músicos se apropian de otras alternativas sónicas y corporales, lo que se evidencia en la manipulación de los equipos tecnológicos, artefactos sonoros y ropas, recurriendo a una estética que no había presenciado ni escuchado en el territorio indígena. 
Estos jóvenes músicos son casi indistinguibles para mí cuando inician estas prácticas sonoro-performáticas en el sótano de la casa. La indumentaria habitual de esa estética punk-rock es ocultada cuando visten en sus cuerpos ch'ullus y sayos $^{20} \mathrm{y}$ el espacio sonoro se manifiesta distinto de lo que hasta el momento mi oído estaba habituado a escuchar en el territorio, con guitarras eléctricas distorsionadas y voces guturales y desaforadas. Es decir, la producción sonora se torna incisiva y disímil al escuchar la amalgama tímbrica entre instrumentos como el charango, la tambora andina y las quenas y zampoñas, con instrumentos eléctricos y electroacústicos, como el bajo y la guitarra.

No obstante, esta metamorfosis sónica/corporal es también sugerente e irreverente, debido a su connotación cosmopolítica que condensa. Es decir, estos jóvenes músicos quieren retornar sonoramente a San Lorenzo ganando aceptación entre sus gobernantes y residentes, pero sin dejar de dar continuidad a ciertas lógicas ontológicas que han venido construyendo como jóvenes músicos emberá chamí. En este sentido, estas prácticas sonoro-performáticas que emergen como símbolo de esas tensiones políticas y generacionales y como elemento contundente visual/sonoro y político/estratégico de representación indígena en el territorio, van a ser visibilizadas a través del nombre de Jaury $^{21}$, nombre que deviene hacia toda una construcción comunitaria sonoro-performativa en el territorio. De esta manera, Jesús, un docente indígena y músico kamentsa ${ }^{22}$, radicado en el territorio indígena desde hace un poco más de ocho años, discurre sobre lo siguiente:

[...] la música andina ${ }^{23}$ es una herramienta, así como que hay muchas cosas para poder llegar a la esencia; es como una ventana, mejor dicho, si no existen las ventanas es difícil que podamos ver afuera, o las puertas para poder entrar o para poder interiorizar también lo propio, para conocerse a uno mismo. Entonces, enseñarles [a ellos] la música andina y la danza andina para que el territorio mire lo bonito que tenemos los pueblos indígenas para mostrar $[\ldots]$

20 El ch'ullu y el sayo forman parte de la tradicional indumentaria andina, especialmente en los Andes peruanos y bolivianos.

21 Jaury es una palabra emberá que significa «fuerza de origen» y es el nombre que dan los jóvenes al grupo musical andino, consolidado un año después -2014- de los sucesos de desterritorialización sónica con las prácticas de punk-rock. Es decir, estos jóvenes sonoramente llevaban un poco más de un año sin prácticas sonoro-musicales en San Lorenzo.

22 Kamentsa son un pueblo indígena de Colombia que habla el camsá y están ubicados en el valle de Sibundoy, en el departamento de Putumayo, en el sur de Colombia, Amazonía colombiana.

23 Por música andina, Jesús se está refiriendo a estas prácticas sonoro-musicales asociadas contemporáneamente a los Andes, aproximadamente en el área dominada por los incas antes del contacto europeo. Esta área incluye la región andina del Perú, el occidente de Bolivia, norte de Chile, norte de Argentina, sierras de Ecuador y suroeste de Colombia. 
yo sé que estos jóvenes tocan géneros urbanos, yo he escuchado algo aquí [en el territorio] pero no me defiendo muy bien con esos tipos de música, yo sí los conocí y ellos tocaban y tenían un buen talento, un potencial por lo disciplinados y por el pensamiento también... tienen un pensamiento muy bonito. En ocasiones, uno ve a estos jóvenes vestidos de negro, con piercing, o con crestas y a veces los juzgamos mal, [pero] todo eso es una energía que ellos tienen para darle a la comunidad, al territorio, al pueblo emberá.

Estas prácticas sonoro-musicales son la evidencia de unas alianzas que se tejen estratégicamente en el territorio, para advertir o sugerir sobre ese conocimiento propio del indígena emberá. Las palabras de Jesús denotan la significación émica para con estas prácticas. Jaury metafóricamente es una «ventana» para que sus dirigentes y residentes puedan ver a través de ella —el afuera y el adentro, lo distante y lo próximo - . Por otro lado, Jaury, pero más precisamente cada uno los jóvenes músicos, deriva cierta continuidad cosmosónica y cosmopolítica que han configurado en el territorio. Como expresa Carlos, músico indígena de este «movimiento» punk-rock e integrante de Jaury:

[...] entonces, con Jaury, los mismos [jóvenes] que hacemos esos eventos [de punk-rock], los mismos... no hemos cambiado, somos todos [...] cuando llega Jesús y nos habla del sistema, pues yo ya conocía el sistema ya conocíamos el sistema y como nos enceguece... entonces el pensamiento del aborigen es crítico y de ahí la lucha, bueno en fin [...] pero ahora con Jaury... decidimos «adornarlo» ese mismo pensamiento que transmitíamos en esos gritos, en las baterías, en esas voces roncas, sí... descubrimos estos ritmos como el tinku ${ }^{24}$ por ejemplo [...] el mismo mensaje está ahí, pero ahora más «adornado» $[\ldots]$ esa misma energía en escenario que transmitimos con las guitarras eléctricas y gritos, esa misma energía la expresamos con las zampoñas, nosotros ya sabemos cómo es que debemos conectar a la gente.

Las descripciones a las que hace mención este joven denotan esa continuidad de lucha y resistencia indígena con las prácticas culturales, manifestaciones recurrentes en el pensamiento de lo que entienden y sienten al hacerse músicos indígenas emberá chamí.

24 Es una danza folklórica del norte de Potosí (Bolivia) que se ha venido expandiendo por todos los Andes. El significado de la palabra tinku es «encuentro» - de la palabra quechua tinkuy, «encontrarse». 


\section{¿MÚSICA ANDINA?}

El resguardo indígena de San Lorenzo es un territorio enmarcado por la cordillera de los Andes. Su posición geográfica y local es distante de lo que contemporáneamente se conoce para con la ejecución de estas prácticas sonoro-musicales, que son precisamente los Andes peruanos y bolivianos. No obstante, cabe mencionar que desde hace décadas estas prácticas andinas vienen teniendo más presencia en la escena musical mundial por la industria, lo que connota difusión por distintos medios locales e internacionales, por lo que sus performances y sonoridades llegan a otras latitudes. En este sentido, algunos grupos peruanos/bolivianos u otros que repercuten representación de estos artistas en otros espacios son evidencia de este impulso y visibilización local e internacional de estas prácticas sonoras andinas, que no solo se disponen con relacionamientos tímbricos reconocibles, sino también con significaciones performáticas/políticas importantes. Por tanto, trabajos como los del etnomusicólogo Tucker (2011), quien trabajó en el Perú acompañando las prácticas sonoro-musicales del grupo Alborada por Europa y los de la antropóloga Bigenho $(2002,2012)$, quien trabajó en Bolivia acompañando las practicas sonoro-musicales del grupo folclórico Música de Maestros, primero en Bolivia y luego en Japón, son la síntesis de lo que acontece sonora y políticamente con estas prácticas musicales andinas y que de una u otra forma han repercutido en otros espacios ${ }^{25}$.

Sin embargo, en el caso de los jóvenes indígenas emberá chamí, no son las prácticas sonoro-musicales andinas dislocadas para otros contextos, como ocurre con Alborada o Música de Maestros. El grupo Jaury reproduce para sí elementos de prácticas sonoro-musicales de otros espacios, es decir, resignifica para con sus performances modelos extranjeros —en este caso de Perú y Bolivia- para intervenir sus prácticas. Los jóvenes asumen este estilo de actuación performático para impulsar con más ahínco una posición con sus prácticas sonoro-musicales en el territorio indígena, debido a que estas prácticas andinas han tenido una repercusión política importante. Como acotan algunos jóvenes: «[...] Nosotros escuchamos por YouTube los grupos, los miramos cómo cantan, nos gusta mucho Kalamarka ${ }^{26}$, las influencias de Jaury vienen por ahí».

25 Es pertinente acotar que, en este sentido, antes de estos autores que cito, muchos otros ya tenían estudiado este fenómeno en las décadas de 1980 y 1990 con la nueva canción y la World Music, como Abercrombie (1991), Baumann (1979, 1981), Béhague (1979), Bellenger (1980, 1981, 1983), Turino (1993) y Romero (2001), entre otros.

26 Es un grupo de música andina boliviana que ya tiene una importante posición en la escena internacional. 
Es pertinente citar en este sentido a Boellstorff (2003), cuando hace mención a «cultura de doblaje». Este autor trae lineamientos en lo que respecta a esta categoría, donde los modelos extranjeros, al ser reelaborados, no permanecen fieles a sus orígenes. Por tanto, cuando estos jóvenes indígenas se apropian de los gestos, palabras, artefactos, movimientos e indumentaria de los grupos andinos peruanos o bolivianos, no se molestan acerca de la «originalidad» o «autenticidad» que ocupan estos materiales encontrados en los medios de comunicación globalizados - YouTube, por ejemplo-. Por lo contrario, hacen uso de ellos para sus propios fines. Siguiendo al autor, «[...] ello agrega un paso, primero alienar algo pero luego re-trabajarlo en un nuevo contexto» (Boellstorff, 2003, p. 237).

Ahora bien, la discontinuidad en este caso se referencia como producto de la «autenticidad» a la que tanto hacen mención la antropología y la etnomusicología con respecto a las prácticas sónicas, y en este caso en particular, de la música andina en un resguardo indígena del centro-occidente colombiano. Antes que nada, quiero acotar que mi intención aquí no es ahondar en un referencial teórico en lo que respecta a esta noción de lo «auténtico»: más bien consiste en delinear ciertas significaciones importantes en la sociabilidad — sociomusical— en torno a estas prácticas sonoro-musicales en el territorio indígena de San Lorenzo; es decir, en lo que respecta — como acota Boellstorff — a los significados émicos para ese «nuevo» contexto. Entonces, ¿por qué estas prácticas son tan aceptadas en el territorio indígena, a pesar de que sus residentes consideran que estas prácticas no son «auténticas» prácticas emberá?

La comprensión de los elementos discursivos y simbólicos que exprimen sentimientos y autenticidades representadas sugiere, dentro de una «comunidad imaginada», cómo las personas piensan sus locales. Según Anderson (1991), la imaginación de una comunidad nacional se encuentra ligada a la matriz ideológica capitalista, inmersa en publicaciones de periódicos y en textos vernáculos, y Bigenho (2002) considera modos alternativos de sentirse miembro de una «comunidad imaginada» a través de la performance musical, unida a las representaciones visuales. En este sentido, mientas que Anderson pone énfasis en la lengua - naciones o comunidades que leen textos comunes-, Bigenho lo hace en naciones o comunidades que oyen, danzan y tocan música.

Estas directrices contornean un poco estas significaciones de las prácticas sonoro-musicales de estos jóvenes; es decir, cómo el territorio indígena entiende su comunidad a partir de estos productos culturales y cómo estos productos o performances han adquirido una enorme legitimidad emocional en estos últimos años. En este sentido, Bigenho (2012) llama «autenticidad única»a que la nueva 
forma tiende a ser innovadora y distinta; además, la autora acota que el cambio engendra una nueva entidad e identidad. Sin embargo, aquí hago mención de que la transformación o metamorfosis o la aparición de un «nuevo» modo de ser y devenir es un proceso que desdibuja cualquier intento de construir una identidad definitiva.

\section{SIMBOLOGÍA REMANENTE DE LA PERFORMANCE: LA MÚSICA ANDINA EN SAN LORENZO}

Los integrantes de Jaury van haciéndose presentes en la tarima, llevando en las manos sus instrumentos musicales y vistiendo en sus cuerpos los ch'ullus y sayos respectivos para iniciar la performance en el centro poblado. Estos jóvenes han dispuesto en el escenario un enorme pilón ${ }^{27}$ con un mortero, debidamente amplificado, precisamente para ofrendar y simbolizar en esta ocasión de performance la semilla, la tierra y el territorio. Así que, con un ritmo lento y constante que uno de los jóvenes produce al chocar el mortero con el pilón, empieza la performance. Después de unos minutos se dirige al micrófono:

Este es un mensaje para cada uno de sus corazones, hombres y mujeres, antes que todo pues darle gracias al gran padre, a la gran madre creadora de... este universo $[\ldots]$ el mensaje, por ahí estamos entregando las semillas... las semillas que gracias a ellas nosotros estamos vivos porque nos dan su alimento... algo de recordar es que somos hijos de esta madre, que nos da todo... y el sentido de las semillas que les estamos dando a las personas que están pasando por ahí es que las sembremos, que no olvidemos esa conexión con nuestra madre por todo lo que es la existencia por todo lo que es el universo... Con ustedes Jaury...fuerza de origen, fuerza de la semilla para cada uno de ustedes y que el universo inunde de felicidad sus corazones.

Estos «nuevos» escenarios de performance de música andina en el territorio asumen ese carácter comunitario en lo que respecta a los procesos de construcción de persona, etnia y territorio. En este sentido, tanto las ofrendas como las oratorias políticas, recurrentes en cada sesión de performance, recrean lineamientos precisos que los residentes del territorio necesitan alimentar y recrear para sentirse miembros de esa «comunidad imaginada».

27 Es un utensilio cilíndrico ahuecado que se usa para hacer la chicha de maíz. Aunque no es frecuente, aún es usado por estas comunidades 

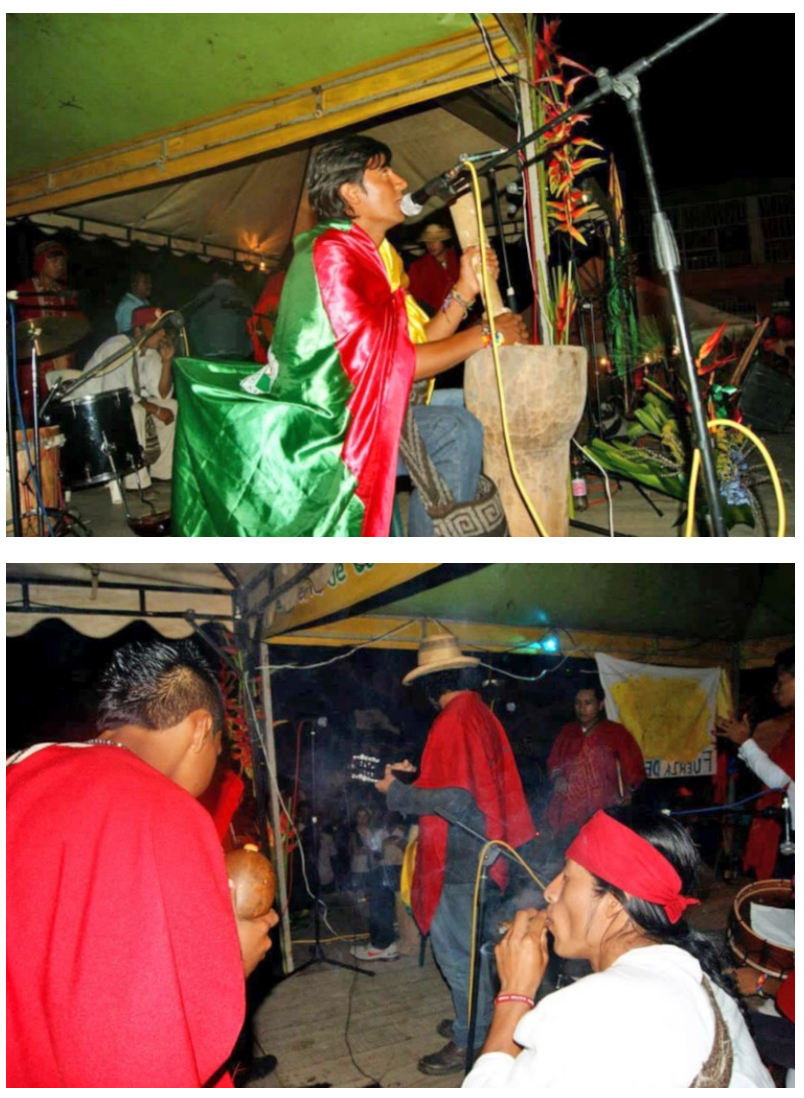

Foto 2. Oratoria política del joven músico en la performance (foto por el autor).

Foto 3. Armonización en la performance de Jaury (foto por el autor).

Posteriormente, en medio de unas luces tenues, entra en el escenario, vestido con un atuendo blanco y exhalando humo de tabaco, un médico tradicional ${ }^{28}$ — chamán - realizando una armonización ${ }^{29}$, práctica recurrente en cada sesión de performance de estos jóvenes. La interpretación en performance de ciertos

28 Es el nombre con el que actualmente en estos territorios indígenas emberá se conoce al chamán o jaibana, precisamente por un conflicto generado décadas anteriores con la Iglesia católica.

29 Esta categoría nativa se refiere a los actos de acción de gracias a la madre tierra que los distintos grupos musicales del territorio realizan. Ella es el núcleo del sistema cosmológico de actuación ecológico-social entre los pueblos indígenas de los Andes centrales de América del Sur. Sin embargo, las armonizaciones son los momentos de iniciación que realiza un médico tradicional — chamán - antes de un evento importante en la comunidad o en las mismas prácticas sonoro-musicales, precisamente para limpiar y purificar el espacio intervenido. Los cuerpos y el mensaje dado — oral o musical — es realizado por el médico tradicional dentro de la misma performance del grupo, fumando tabaco e interpretando algunos artefactos sonoros, donde emite sonidos y entonaciones vocales propias del chamanismo. 
artefactos sonoros - recurrente en las prácticas chamánicas - amplificados ${ }^{30}$, en conjunto con las melodías de las quenas y zampoñas y la incisiva percusión de la batería y tambora, hacen el ambiente sonoro muy denso, lo que se manifiesta en los asistentes por percepciones simbólicas de representación indígena.

Esta armonización es conectada posteriormente con las distintas canciones del grupo, que mediante sanjuanitos, tinkus y sayas ${ }^{31}$ evocan toda una manifestación cultural andina en el territorio.

En su trabajo entre el Perú y Bolivia, Bigenho (2002) interpela el interrogante: ¿qué te hace querer danzar? Esta autora discurre en la «autenticidad» de la experiencia misma, lo que implica el carácter real de sentir en el cuerpo. Es decir, el aspecto esperado visual y sónico de la performance inspira los movimientos y la danza, evocando una experiencia «auténtica» delineada por la misma experiencia sinestésica. En este sentido, podemos incurrir igualmente en esa densidad semiótica de la performance, como menciona Turino (2008) cuando hace alusión a la «sincronía musical». Es decir, al evento representado como una performance en sociedad, una sincronización de cada una de las acciones de los individuos dada por las percepciones de los sonidos y la performance.

Ahora bien, es pertinente acotar que estas «estrategias» políticas de apropiación por estos jóvenes músicos, con estas prácticas sonoro-musicales de mestizos peruanos y bolivianos, están dentro de un imaginario actual como «auténticas» prácticas indígenas. En este sentido, toda la disposición sónica en la que se encuentran y se disponen estas prácticas sonoras en el territorio conducen a que los gobernantes y residentes las promulguen como tales. Bigenho (2012) se refiere al concepto de «distancia íntima» -intimate distance-, cuyos términos aparecen asociados a otras dos categorías de corte más bien psicológico: «deseo y miedo, intimidad y distancia». Este oxímoron respondería justamente a la contradicción aparente entre una conexión afectiva — incluso corporal— con un otro y el sentimiento de ser muy distinto de este. Es decir, como bien definen estos jóvenes emberá, al referirse metafóricamente a que sus prácticas sonoromusicales son como una «ventana». Existe una conexión muy profunda con estas prácticas andinas peruanas y bolivianas, pero aun así, los conduce a cuestionarse en lo que verdaderamente los vincula como sociedad emberá chamí.

30 Algunos de los artefactos sonoros usados son la armónica, los cascabeles y el atekokoli. Este último, es un caracol que el médico tradicional usa soplando por una de las hendiduras y produciendo un sonido similar al de un cuerno.

31 Son algunos géneros de música peruana-boliviana que este grupo evoca e incorpora en sus performances por la circulación cultural andina. 


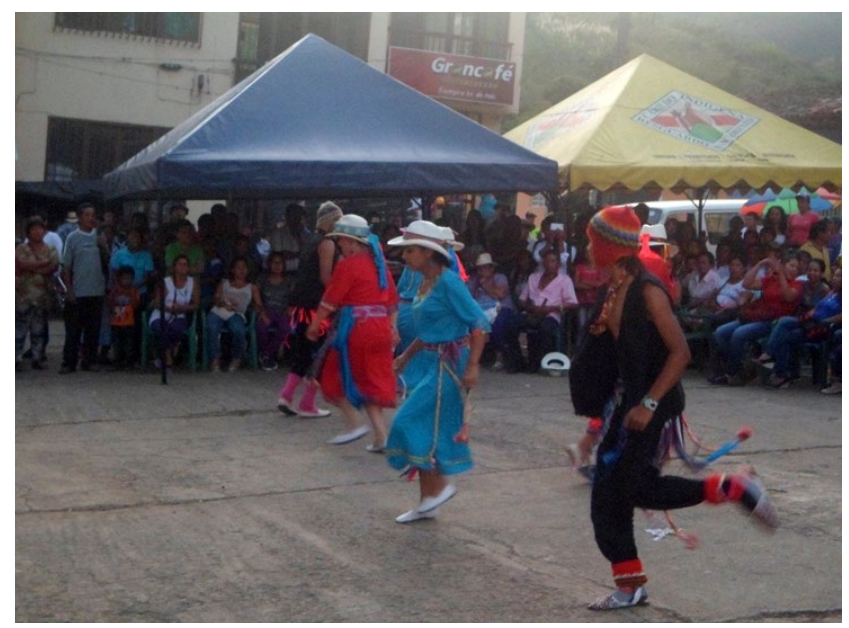

Foto 4. Danza andina en las fiestas del resguardo (foto por el autor).

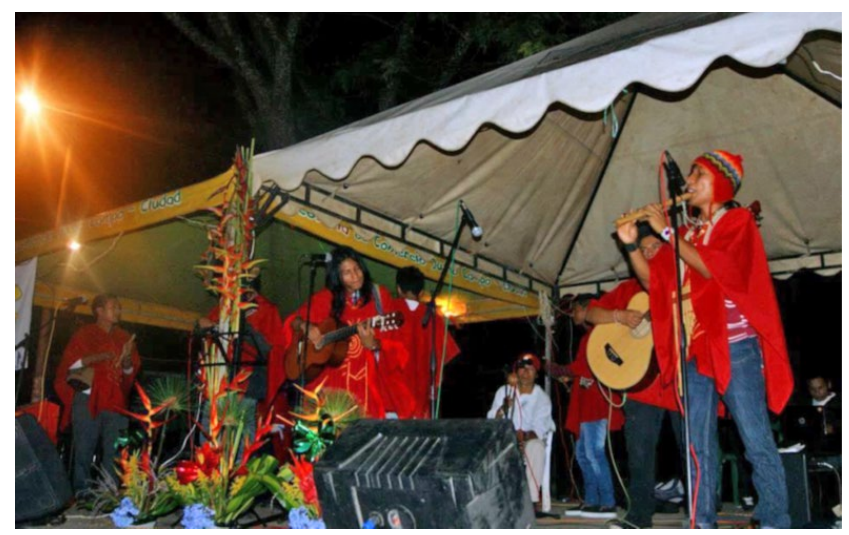

Foto 5. Performance de Jaury. Parque de San Lorenzo (foto por el autor).

\section{CONCLUSIONES}

Los jóvenes indígenas emberá chamí están elaborando otro camino de lucha y resistencia, y para que sus voces sean escuchadas, las promulgan con sus prácticas sonoro performáticas. Este activismo indígena e inusitado en los Andes colombianos se evidencia por ciertas dimensiones estéticas-estilísticas que naturalizaron y legitimaron en toda una trayectoria de vida musical en el territorio indígena y que sopesaron para generar una indigenidad emergente capaz de provocar o instigar en la política contemporánea.

Las prácticas culturales indígenas emberá continúan rezagadas a simples creencias folclóricas, que únicamente se mercantilizan como atracción turística y que por ningún motivo deben ser llevadas a la política. En este sentido, estos 
jóvenes músicos se encauzan para balancear esto, intentando entrever una política diferente; se ahíncan con más vehemencia para que sus voces, sus oratorias políticas y sus prácticas sonoro-performáticas sean escuchadas para ciertos propósitos e intereses comunitarios. La apropiación de prácticas sonoras de la industria de la música, como el punk-rock y la música andina, y de algunos artefactos sonoros eléctricos y tecnológicos, es la estrategia para este diálogo cosmopolítico emberá. Como expresan algunos jóvenes, «[...] esta es nuestra lucha y recién comienza, no armada, sino a través de la palabra y el canto».

El modo de ser/estar indígena de estos jóvenes se evidencia a través de ciertas performances identitarias que han consolidado por la escucha y práctica del punkrock y vinculada posteriormente por estrategia cosmopolítica con las prácticas de música andina. En otras palabras, los impulsivos y contrastantes sonidos, las distintas tecnicalidades ${ }^{32}$ y los excesivos movimientos corporales son el insumo de significaciones en performance que estos jóvenes delinean en cada espacio con cualquiera de sus prácticas sonoro-musicales. Es solamente haciendo suficiente «ruido» que estas sociedades indígenas, históricamente subalternas, pueden ser escuchadas.

En suma, esta densidad semiótica se explora en dos planos: la apropiación del punk-rock como símbolo de lucha y resistencia indígena hasta la apropiación de la música andina como «estrategia» de representación indígena en el territorio.

\section{REFERENCIAS BIBLIOGRÁFICAS}

Anderson, Benedict (1991). Imagined Comumunities: Reflections on the Origin and Spread of Nationalism, revised edition. Londres: Verso.

Bigenho, Michelle (2002). Sounding Indigenous: Authenticity in Bolivian Music Performance. Nueva York: Palgrave Macmillan. https://doi.org/10.1007/978-1137-11813-4

Bigenho, Michelle (2012). Intimate Distance. Andean Music in Japan. Durham: Duke University Press. https://doi.org/10.1215/9780822395317

Boellstorff, Tom (2003). Dubbing culture: Indonesian Gay and Lesbian Subjectivities and Ethnography in an already globalized world. American Ethnologist, 30(2), 225-242. https://doi.org/10.1525/ae.2003.30.2.225

32 Llamo tecnicalidades a las distintas formas ontológicas de aprendizaje dadas en el territorio indígena para con estos instrumentos musicales y artefactos tecnológicos. 
Deleuze, Gilles y Félix Guattari (1996). Mil Platôs: capitalismo e esquizofrenia. Vol. 3. Rio de Janeiro: Ed. 34.

Ferreira, Pedro (2006). Música eletrônica e xamanismo: Técnicas Contemporâneas do Extase. Tesis de doctorado en Ciencias Sociales. São Paulo: Universidade Estadual de Campinas.

Guattari, Félix y S. Rolnik (1996). Micropolítica: cartografias do desejo. Petrópolis: Vozes.

Kafka, Franz (1988[1915]). La metamorfosis. Bogotá: Alianza Editorial.

Kosik, Karel (1996). O século de Grete Samsa: sobre a possibilidade ou a impossibilidade do trágico no nosso tempo. Traducción de Leandro Konder. Matraga, 8, 9-17.

Seeger, Anthony (2008). Etnografia da música. Cadernos de campo, 17, 237-259. São Paulo.

Stein, Marilia (2009). Kyringüé in Mboraí - os cantos das crianças e a cosmo-sônica Mbyá - Guarani. Tesis de doctorado en Etnomusicologia/Musicologia. Universidade Federal de Rio Grande do Sul. Porto Alegre. Recuperado el 12 de abril de 2015 de http://hdl.handle.net/10183/17304.

Taussig, Michael (1993). Mimesis and Alterity. A Particular History of the Senses. Nueva York: Routledge.

Tucker, Joshua (2011). Permitted Indians and Popular Music in Contemporary Peru: The Poetics and Politics. Ethnomusicology, 55(3), 387-413. https://doi.org/10.5406/ ethnomusicology.55.3.0387

Turino, Thomas (2008). Music as Social Life: the politics of participation: Chicago: University of Chicago Press. 